\title{
How events are reviewed matters: Effects of varied focus on eyewitness suggestibility
}

\author{
SEAN M. LANE \\ University of Nevada, Las Vegas, Nevada \\ MARA MATHER \\ University of California, Santa Cruz, California \\ DIANE VILLA \\ Saint Louis University, St. Louis, Missouri \\ and \\ SHELBY K. MORITA \\ Wells Fargo, San Francisco, California
}

\begin{abstract}
Witnesses to a crime or an accident perceive that event only once, but they are likely to think or talk about it multiple times. The way in which they review the event may affect their later memory. In particular, some types of review may increase suggestibility if the witness has been exposed to postevent misleading information. In Experiment 1, participants viewed a videotaped crime and then received false suggestions about the event. We found that participants who were then asked to focus on specific details when reviewing the event were more suggestible on a later source memory test than participants asked to review the main points. The findings of Experiment 2 suggest that this effect was not due to a criterion shift at test. These findings indicate that the type of rehearsal engaged in after witnessing an event can hame important consequences for memory and, in particular, suggestibility.
\end{abstract}

Although witnesses to a crime or an accident perceive that event only once, they are likely to think about it multiple times afterward. Sometimes this may occur as a result of direct questioning by law enforcement personnel, lawyers, reporters, and so forth. On other occasions, they may think about the event because it was particularly salient or highly emotional. Witnesses may also deliberately review the event because they realize that they will be asked to recount it to the authorities and want to ensure the accuracy of their story. Thus, at any given time, witnesses might think about the original event for different reasons or goals. Because of this, their review might focus on different aspects of the event or involve different levels of specificity. How an event is reviewed has the potential to strengthen, embellish, or distort various aspects of the memory representation and thus could ultimately influence the accuracy of a witness's report. The aim of

The authors thank Erin Warnick, Melissa Guerrica, Amy Clark, Jeff Freehill, Sherry Gilbert, Dianne Learned, Paul Shupe, Faith Yew, Monika Ferroni, Farah Lewis, Charlote Mullee, and Jenna Sheldon for their help collecting the data. We also thank Karen Mitchell and Marcia Johnson for their helpful comments on an earlier draft of this manuscript. Correspondence concerning this article should be addressed to S. M. Lane, Exponent, Inc., 149 Commonwealth Drive, Menlo Park, CA 94025 (e-mail: sean_m_lane@yahoo.com), or M. Mather, Psychology Department, 357 Social Sciences II, University of California, Santa Cruz, CA 95064 (e-mail: mather@cats.ucsc.edu). the present study was to examine how reviewing an eyewitness event affects later memory for that event.

There is a substantial literature concerning how repeated review, testing, or questioning affects memory performance. For instance, autobiographical memory research has revealed that the more a person thinks or talks about a particular event, the more likely that he/she will remember it later and the more vivid it will seem (see, e.g., Rabbitt \& Winthrope, 1988; Suengas \& Johnson, 1988; Tessler \& Nelson, 1994). In list-learning studies, testing memory soon after acquisition increases the likelihood that the information will later be recalled or recognized (the testing effect; see, e.g., Brainerd, Reyna, Howe, \& Kingma, 1990; Hogan \& Kintsch, 1971). In addition, repeated testing often leads participants to recall previously unrecalled material ("reminiscence"; e.g., Payne, 1987; Richardson, 1985). In some cases, reminiscence exceeds the rate of forgetting on a given trial ("hypermnesia"; e.g., Erdelyi, 1996; Erdelyi \& Becker, 1974; Payne, 1987). The same effects have been demonstrated in eyewitness memory studies (Bornstein, Liebel, \& Scarberry, 1998; Dunning \& Stern, 1992; Scrivner \& Safer, 1988). For example, Scrivner and Safer (1988) found that adults repeatedly questioned (nonsuggestively) about a simulated burglary showed hypermnesia across four recall tests. The basic finding of better event memory with repeated testing has been replicated numerous times (e.g., Fivush \& Hamond, 1989; Howe, 1991; Poole \& White, 1991; Warren \& Lane, 1995). 
However, the effects of repeated testing or questioning are not uniformly positive. For example, errors that occur on an early recall test tend to persist on later recall trials even if the original stimuli are re-presented (Howe, 1970; Kay, 1955). Repeated testing also appears to increase the number of extra-event intrusions recalled in eyewitness studies (e.g., Eugenio, Buckhout, Kostes, \& Ellison, 1982; Fivush \& Hamond, 1989). Finally, the act of recalling information can sometimes lead to poorer memory for unrecalled information (output interference or retrieval inhibition; see, e.g., Koutstaal, Schacter, Johnson, \& Galluccio, 1999; Roediger \& Neely, 1982; Shaw, Bjork, \& Handal, 1995).

Understanding the effects of postevent reviews on eyewitness memory is further complicated by the fact that witnesses can be exposed to misleading postevent information, as, for instance, during contact with other witnesses, while reading media accounts of the event, or during interactions with law enforcement personnel or attorneys. The effect of misleading postevent information on eyewitness memory is well established. In a typical experiment, participants view a simulated crime presented on videotape or slides. Later, these witnesses answer a series of questions about the event or read a narrative that describes it. Embedded within these questions or narratives are items that they did not witness in the context of the event. The participants subsequently receive a memory test that includes both items that actually were in the witnessed event and items that were only suggested. The misinformation effect is the finding that participants routinely report having seen items in the witnessed event that have in fact only been suggested to them (e.g., Lindsay, 1990; Loftus, Miller, \& Burns, 1978; McCloskey \& Zaragoza, 1985; Zaragoza \& Lane, 1994).

The size of the misinformation effect can vary, depending on the conditions during suggestion or immediately afterward. For example, the effect is greater with repeated suggestion (Mitchell \& Zaragoza, 1996; Zaragoza $\&$ Mitchell, 1996). Furthermore, conditions that lead participants to commit to (e.g., Schooler, Foster, \& Loftus, 1988) or retrieve the suggestions (Roediger, Jacoby, \& McDermott, 1996) increase suggestibility. For instance, Roediger et al. had participants view an eyewitness event and then read a narrative describing the event that contained misleading information. The participants then completed a cued recall test that instructed them to answer questions with either (1) information that they were sure they saw only in the original event, or (2) information obtained from either source. As would be expected, the participants were more likely to produce misleading information when given the latter instructions, presumably because of the more lenient criterion. Two days later, the participants completed a second cued recall test that instructed them to ignore the postevent information and to respond only on the basis of what they had seen in the original event. Despite the test instruction, participants who had initially recalled the misleading detail on the first cued recall test were more likely to produce it on the second test (for a related finding with an initial recognition test, see Schooler et al., 1988). Taken together, this research suggests that the effect of reviewing on eyewitness memory may be complicated by whether or not the witness has been exposed to misleading postevent information. Specifically, reviewing the event could have the unintended effect of increasing the probability that witnesses will incorporate the misleading information into accounts of what they have witnessed.

In the following study, we manipulated the specificity of the review that participants engaged in subsequent to exposure to misleading information. We were most interested in the consequences of this manipulation on participants' attributions of the misleading information to the witnessed event. Participants viewed a videotape of a simulated crime and then answered a series of questions about the event. Embedded within these questions were misleading suggested items that were not true of the event that they had seen (e.g., that the thief took a ring). These items were suggested either one or three times. ${ }^{1}$ The primary manipulation concerned the task that the participants were given during the period between postevent questioning and a final memory test (in Experiment 2, this manipulation took place before postevent questioning). In the detail review condition, the participants were told to review the events in the video in a detailed manner and to write down as many specific details as they could remember. In the summary review condition, the participants were told to review only the most important aspects of the event in the video and to write down a summary of the event that did not include unnecessary detail. In the no-review (control) condition, the participants did not review the event. In the last phase of the experiment, all participants received a source memory test that involved answering two questions about each item: (1) Did you see or hear the information in the video? and (2) Did you read about the information in the questions you answered earlier?

One possible outcome of manipulating the specificity of review was that summary review would lead to higher suggestibility than would detail review. Summary review instructions could lead participants to form only a schematic representation of the witnessed event, which would make them more likely to claim that they had witnessed schemaconsistent misleading details. In contrast, detail review instructions should lead participants to encode a richer representation of the event, which would help them notice inconsistencies between event and misleading postevent details. Participants who scrutinize postevent information as they read it tend to be more resistant to misleading postevent information (i.e., discrepancy detection; Tousignant, Hall, \& Loftus, 1986).

In our study, however, unlike in Tousignant et al. (1986), the scrutiny that occurred during detail review would occur after the suggestions had already been read. Previous research has indicated that participants have difficulty rejecting postevent misleading information unless they are provided with highly salient warnings immedi- 
ately after exposure (Chambers \& Zaragoza, 1993; Greene, Flynn, \& Loftus, 1982). Thus, we predicted that after encountering the suggestions, engaging in a detailed review would not help the participants detect discrepancies. Instead, asking the participants to review specific details should make suggested items (which tend to be peripheral details rather than central information in the event) more likely to come to mind. Retrieving these details would make it more likely that participants would later claim to have seen the misleading items (Roediger et al., 1996). Such errors can be interpreted as source misattributions, in that witnesses are misattributing misleading information from a postevent source to the event (e.g., Lindsay, 1990; Zaragoza \& Lane, 1994; for a more general review, see Johnson, Hashtroudi, \& Lindsay, 1993). A summary review, on the other hand, is less likely to lead to rehearsal of the suggestions, and thus these participants should be less prone to source misattributions later, when asked whether a suggestion was in the video.

\section{EXPERIMENT 1}

\section{Method}

Participants. Two hundred-seventy undergraduate students from the University of Nevada, Las Vegas participated in partial fulfillment of a class credit. Ninety participants were randomly assigned to each of the three experimental conditions.

Materials. The eyewitness event was a 5-min videotaped simulation of a burglary and a car chase (see Zaragoza \& Mitchell, 1996). The videotape was shown on a 27 -in. color monitor.

The postevent questionnaire consisted of 37 questions about the video. Embedded within these questions were misleading items that had not been seen in the video. These items supplemented rather than contradicted what had been seen, and the items were not the object of the questions. For example, for the suggestion "the thief wore gloves," the participants were asked, "At the beginning of the scene, a young man dressed in jeans, a t-shirt and gloves entered the house. Did he enter through the door?" Across the experiment, there were a total of 12 critical items (statements): The thief wore gloves, the driver smoked a cigarette, the police thought the driver was DWI, the thief had a gun, the neighbor's name was Mrs. Anderson, one of the police officers was drinking coffee, the thief took a ring, the thief pulled a window shade down, the driver jumped the curb with the car, the police said they would shoot, the thief put on his seatbelt, and there was a barking dog. There were three versions of the questionnaire, and in any given version 4 critical items functioned as never presented control items (i.e., they did not appear until the final test), 4 critical items functioned as once suggested items, and 4 critical items functioned as thrice suggested items. An equal number of participants in each condition received each version.

The source test consisted of 32 test statements read aloud by the experimenter. Eight of the statements had been suggested only in the postevent questions ( 4 had been suggested once, and 4 were suggested three times), 4 statements were critical items that had never been suggested (control items), 4 statements were filler items that had never been seen or suggested, 8 were statements that reflected events that were only seen in the video, and 8 items were seen in the video and read about in the questions.

Procedure. The experimental procedure is outlined in Table 1. The participants were run in groups of 6-8. First they viewed the video of a robbery, and immediately afterward, they completed the postevent questionnaire. The participants were warned that because the video contained so many details, they might have to answer more than one question about some events or parts of the film, but that they were not to go back and check previous answers.

Following completion of the postevent questionnaire, the participants in the detail review and summary review conditions first worked on a word-search puzzle as a filler task for $5 \mathrm{~min}$. Both conditions next received instructions about reviewing the events in the video that they had watched earlier in the session. The participants in the detail review condition were told to mentally review these events in a very detailed manner, and to think about and write down as many specific details as they could remember. They were also informed that they would have $5 \mathrm{~min}$ to complete the task. The participants in the summary review condition were treated identically, except that they were instructed to focus their review only on the most important aspects of the events in the video. That is, the participants in this condition were told to think about and write down a summary of the events that did not include unnecessary detail. Following the review period, the participants in both review conditions returned to the word-search puzzle task for an additional $5 \mathrm{~min}$. The participants in the no-review (control) condition simply worked on the word-search puzzle task for the full $16 \mathrm{~min}$.

All participants next received instructions for the source test. They were first told that some of the test statements contained information that they only saw in the video, some contained information that was only in the questions that they read and answered, some contained information from both the video and the questions, and some contained new information. They were further instructed that their task was to indicate what they remembered about the source of the information for each test item. For the source test, 32 statements

Table 1

Experimental Procedure, Experiments 1-2

\begin{tabular}{|c|c|c|c|c|c|c|}
\hline \multirow[b]{2}{*}{ Condition } & \multicolumn{6}{|c|}{ Phase } \\
\hline & 1 & 2 & 3 & 4 & 5 & 6 \\
\hline \multicolumn{7}{|l|}{ Experiment 1} \\
\hline Detail review & video & questions & 5 -min filler & $\begin{array}{l}\text { 1-min review instructions }+ \\
5 \text {-min detail review }\end{array}$ & 5 -min filler & source test \\
\hline Summary review & video & questions & 5 -min filler & $\begin{array}{l}\text { 1-min review instructions }+ \\
5 \text {-min summary review }\end{array}$ & 5 -min filler & source test \\
\hline No review & video & questions & 16-min filler & - & - & source test \\
\hline \multicolumn{7}{|l|}{ Experiment 2} \\
\hline Detail review & video & 5 -min filler & $\begin{array}{l}\text { 1-min review instructions }+ \\
5 \text {-min detail review }\end{array}$ & questions & 5 -min filler & source test \\
\hline Summary review & video & 5 -min filler & $\begin{array}{c}\text { 1-min review instructions }+ \\
5 \text {-min summary review }\end{array}$ & questions & 5 -min filler & source test \\
\hline No review & video & 11-min filler & - & questions & 5-min filler & source test \\
\hline
\end{tabular}


were read aloud, and the participants were asked to answer two questions about each statement: (1) Did you see or hear the information in the video? and (2) Did you read about the information in the questions you read and answered earlier? ${ }^{2}$ The participants indicated their answer to each question on a 7-point Likert-type scale with the following response options: definitely yes, probably yes, maybe yes, unsure, maybe no, probably no, and definitely no. The unsure response was provided to minimize guessing.

\section{Results}

The main dependent variable of interest was the proportion of "yes" responses made to a given source (e.g., the number of suggested items attributed to the video/the total number of suggested items). The results are simplified by several findings. First, because there was no main effect for confidence level or any interaction, we report the participants' responses pooled across confidence level. Thus, the dependent variables of interest were all "video" or "questions" responses (definitely + probably + maybe yes). Second, although the participants were in general more suggestible for items suggested three times $(M=.49, S E=$ $.02)$ than for those suggested once $(M=.33, S E=.02)$ $[F(1,267)=64.50, p<.001]$, repetition did not interact with type of review in any analysis, and thus we report the results pooled across once and thrice suggested items.

Attribution of items to the video. The primary data of interest is reported in Table 2. In one-way analyses of variance (ANOVAs), the proportion of items on the memory test from the video that were correctly attributed to the video did not significantly differ by group, nor did the proportion of control (never presented) items attributed to the video.

Nevertheless, the type of review did affect the proportion of suggested items that participants attributed to the

Table 2

Attributions of Video, Suggested, and Control Items to the Video and to the Questions in Experiments 1 and 2

Type of Review

\begin{tabular}{|c|c|c|}
\hline None & Summary & Detail \\
\hline$M \quad S E M$ & $M \quad S E M$ & $S E M$ \\
\hline
\end{tabular}

Experiment 1

Attributions to the video

Video only items

Suggested items

Control items

\section{$.86 \quad .01$}

$.42 \quad .03$

$.11 \quad .02$

Attributions to the questions

Video only items

Suggested items

Control items

Attributions to the video

$\begin{array}{lllllll}\text { Video only items } & .83 & .01 & .85 & .01 & .82 & .02 \\ \text { Suggested items } & .37 & .03 & .34 & .03 & .35 & .03 \\ \quad \begin{array}{l}\text { Control items } \\ \text { Attributions to the questions }\end{array} & .13 & .02 & .11 & .02 & .10 & .02 \\ \quad & & & & & \\ \text { Video only items } & .12 & .02 & .17 & .02 & .20 & .03 \\ \text { Suggested items } & .74 & .02 & .79 & .02 & .79 & .02 \\ \text { Control items } & .03 & .01 & .06 & .02 & .05 & .02\end{array}$

$* n=90$ for each condition in Experiment $1 . \quad \hbar n=72$ for each condition in Experiment 2. video $[F(2,267)=4.20, p<.05] .^{3}$ A post hoc Tukey test revealed that detail review participants were significantly more likely than summary review participants to misattribute suggested items to the video. No-review participants' proportion of misattributions was between the other two groups' and not significantly different from that of either group.

Attribution of items to the questions. There were no significant differences between the groups for the proportion of video, control, or suggested items attributed to the questions (all $F_{\mathrm{S}}<1$; see Table 2 for means).

The content of reviews. Two scorers counted the total number of words used and the proportion of test items of each type (i.e., both, video, suggested, control, and filler items) that were mentioned in each participant's written review. Initially, there was $83 \%$ interrater agreement. Disagreements were resolved by one of the authors in consultation with the scorers.

Participants in the detail condition used more words in their reviews $(M=129.21$ words, $S E=2.69)$ than did the summary review participants $(M=117.82$ words, $S E=$ 2.69) $[t(178)=3.0, p<.003]$. In addition (see Table 3 ), the detail review participants mentioned a higher proportion of both (video and questions) items than did the summary review participants $[t(178)=4.20, p<.001]$, and a higher proportion of video-only items than did summary review participants $[t(178)=2.81, p<.01]$. The detail review participants also mentioned a higher proportion of suggested items than did the summary review participants $[t(178)=2.02, p<.05]$. The groups did not differ in the number of control items that they mentioned in their written reviews, and no participants in either group mentioned any filler items.

The effect of mentioning an item on source memory. To determine whether mentioning a particular item in the review increased the likelihood that it would later be attributed to the video, we calculated both the average proportion of mentioned items and the average proportion of nonmentioned items (video or suggested) that were attributed to the video for each participant. For each type of item, we included only the participants who had mentioned at least one item of that type. These means are presented in the top section of Table 4, along with the number of participants included in the analysis for each type of item.

For video items, a 2 (review condition: summary, detail) $\times 2$ (mentioning item: not mentioned, mentioned) ANOVA revealed a main effect of mentioning the item $[F(1,124)=$ $56.49, p<.001]$, with items that were mentioned more likely to be attributed to the video than items that were not. There was no effect of condition and no interaction. The same ANOVA for participants who mentioned any suggested items revealed a main effect of mentioning suggested items $[F(1,58)=11.68, p<.01]$. Participants who mentioned items were more likely to attribute those items to the video than the items they had not mentioned. There was no significant effect of condition or interaction of condition with mentioning the items. 
Table 3

Average Proportions of Both Video and Questions, Video, Suggested, Control, and Filler Items Mentioned in Participants' Written Reviews

\begin{tabular}{llllll}
\hline & \multicolumn{2}{c}{ Summary Review } & & \multicolumn{2}{c}{ Detail Review } \\
\cline { 2 - 3 } \cline { 5 - 6 } Item Type & $M$ & SEM & & $M$ & SEM \\
\hline Both in video & & & & \\
$\quad$ and questions & .23 & .02 & .34 & .02 \\
Video only & .13 & .01 & .19 & .01 \\
Suggested & .04 & .01 & .06 & .01 \\
Control & .01 & .00 & .01 & .00 \\
Filler & .00 & .00 & .00 & .00 \\
\hline
\end{tabular}

Participants who did not mention any suggested items. Participants who did not mention any items of a particular type in their reviews could not contribute to the preceding analyses (which included a within-subjects factor of whether or not items were mentioned). However, it is interesting to look at the average number of items attributed to the video among these participants (see Table 4). Did being in the detail review condition increase the likelihood of attributing suggested items to the video even if these items were not mentioned? Not every item that was thought about may have been written down. If detail review participants thought about more suggested items than did summary review participants, they might show higher rates of misattributions for these items even when they did not mention any of the suggested items. This appears to have been the case. Among participants who did not mention any suggested items, detail review participants were more likely than summary review participants to attribute the suggestions to the video $[t(118)=2.23$, $p<.05]$.

Comparison of those who mentioned suggested items and those who did not. Participants who mentioned any suggested items at all in their written reviews might have differed from participants who did not mention any suggested items. For instance, they might either have been oriented more toward thinking about and reviewing details of the event, or they might have been the set of participants who had the most difficulty distinguishing suggestions from the actual video material. In either case, this could have led them to be more likely to misattribute any suggested item to the video than participants who did not mention any suggestions. Thus, they might show elevated misattributions even for the suggestions they did not mention in their reviews. To investigate this possibility, we conducted a 2 (review condition: summary, detail) $\times 2$ (mentioning any items: none mentioned, any mentioned) ANOVA with the proportion of nonmentioned suggested items attributed to the video as the dependent variable (see Table 4 for the means, which are listed in the "Not Mentioned" columns). There was a main effect of condition, $[F(1,176)=4.58, p<.05]$, with detail review participants more likely to attribute suggested items to the video than summary review participants. There was also a main effect of mentioning any items $[F(1,176)=4.15$, $p<.05]$. Participants who had mentioned at least one suggested item in their review misattributed .46 of the suggested items they had not mentioned to the video. In contrast, participants who had not mentioned a single suggested item in their review only misattributed .37 of the suggested items to the video. Thus participants who mentioned suggested items in their review had not only a higher rate of misattributions for mentioned items, but also a higher rate of misattributions for suggested items that they did not mention.

\section{Discussion}

The results of this experiment demonstrate that all forms of review are not created equal with respect to their effects on eyewitness suggestibility. Specifically, participants who focused on reviewing the specific details of a witnessed event were more likely than participants who focused on summarizing the most important details to (1) include previously encountered misleading postevent information in their written review and (2) mistakenly attribute this information to the eyewitness event at test. Detail review participants were also more likely to misattribute suggested items to the video than summary review participants, even if they did not produce the specific item in their review. Thus, memory for a witnessed event can be affected by the specificity of a review.

One question to emerge from Experiment 1 concerns the low levels with which the participants mentioned suggested items in the context of their reviews (see Table 3).

Table 4

Average Proportion of Items Not Mentioned and Mentioned in Participants' Written Reviews That Were Later Attributed to the Video

\begin{tabular}{|c|c|c|c|c|c|c|c|c|c|c|}
\hline \multirow[b]{3}{*}{ Item Type } & \multirow[b]{3}{*}{$n$} & \multicolumn{4}{|c|}{ Summary Review } & \multirow[b]{3}{*}{$n$} & \multicolumn{4}{|c|}{ Detail Review } \\
\hline & & \multicolumn{2}{|c|}{ Not Mentioned } & \multicolumn{2}{|c|}{ Mentioned } & & \multicolumn{2}{|c|}{ Not Mentioned } & \multicolumn{2}{|c|}{ Mentioned } \\
\hline & & $M$ & SEM & $M$ & $\overline{S E M}$ & & $M$ & $\overline{S E M}$ & $M$ & SEM \\
\hline \multicolumn{11}{|c|}{ Participants Who Mentioned Items in Their Review } \\
\hline Video only & 57 & .84 & .02 & .97 & .02 & 69 & .84 & .02 & 1.00 & .02 \\
\hline Suggested & 25 & .42 & .05 & .56 & .09 & 35 & .50 & .04 & .74 & .08 \\
\hline \multicolumn{11}{|c|}{ Participants Who Did Not Mention Any Items } \\
\hline Video only & 33 & .83 & .02 & & & 21 & .77 & .03 & & \\
\hline Suggested & 65 & .32 & .03 & & & 55 & .43 & .04 & & \\
\hline
\end{tabular}


Keep in mind that the suggested items were fairly peripheral details in the context of the entire witnessed event, and that they were not the direct object of postevent questions. The participants had only 5 min to construct their written reviews, so that it would have been unlikely for even a relatively detailed review of the event to cover many of these items. Furthermore, even items that were encountered in both the video and the questions were at best mentioned by participants only one third of the time. Perhaps most interesting is the finding that the process of producing a detailed review led to increased source misattribution errors even when the suggested items were not mentioned in the review.

\section{EXPERIMENT 2}

We suggest that, in Experiment 1, detail review participants were more suggestible than summary review participants, because they were more likely than summary review participants to have postevent misleading items come to mind while reviewing the video, leading to a higher probability for source misattributions later. However, another possibility was that the different review instructions led to different biases about the type of information to accept on the source test. If participants asked to write a summary of the video believed that the experimenters were interested only in central information from the video, they might have been less likely to attribute more peripheral details (including suggested items) to the video on the source test. In contrast, participants asked to review the details might have believed that they should be inclusive about what they remembered, both during the review and on the later source test.

To test whether the increased suggestibility in the detail review condition was the result of a criterion shift on the source test rather than the result of reviewing suggested items, in Experiment 2 participants were asked to review the events in the video before receiving the postevent questionnaire. Reviewing the video before receiving suggestions should make it extremely unlikely that participants would rehearse suggested information along with information actually from the video. Thus, if our finding of greater suggestibility for detail review participants than for summary review participants in Experiment 1 was due to the type of information that was reviewed, we should not find this effect in Experiment 2. In contrast, if our instructions led participants to interpret the experimental demands differently (i.e., setting a different criterion for the type of information they were willing to attribute to the video), we should find the same differences in suggestibility in Experiment 2 as in Experiment 1, because giving the review instructions before the suggestions should convey the same experimental demands as would giving them after the suggestions.

\section{Method}

Participants. Two hundred and sixteen undergraduate students from the University of Nevada, Las Vegas participated in partial fulfillment of a class credit. Seventy-two participants were randomly assigned to each of the three experimental conditions.

Materials and Procedure. The materials and procedure were the same as in Experiment 1, except that the order of the experimental tasks was changed (see Table 1). Participants in the review conditions (1) watched the video of a robbery; (2) completed a 5-min filler task; (3) were given review instructions (for about $1 \mathrm{~min}$ ) and then had 5 min to complete their review; (4) were given the postevent questions that included some false suggestions about the video; (5) completed a 5-min filler task; (6) completed the source test. In the control condition, Steps 2 and 3 were combined for an 11-min filler task.

\section{Results}

For the same reasons as in Experiment 1, the participants' responses were pooled across confidence level and across once and thrice suggested items. The means are presented in Table 2. The main finding of interest was that, unlike in Experiment 1, the type of review did not affect the proportion of suggested items that participants attributed to the video $[F(2,213)=0.19]$. The type of review also did not significantly affect the proportion of video or control items attributed to the video, or the proportion of video, control, or suggested items attributed to the questions.

\section{Discussion}

Experiment 2 revealed that reviewing the details of an event before receiving false suggestions did not affect participants' later likelihood of attributing the suggestions to the video. In contrast, in Experiment 1, reviewing the details of the video after receiving false suggestions about it increased participants' tendency to attribute the suggested details to the video. Thus engaging in a detailed review seems to lead to increased suggestibility only if the review occurs after the suggestions have already been experienced-giving further evidence that the increase in suggestibility after detail review in Experiment 1 was due to reviewing the suggestions, rather than to participants' interpretation of the experimental demands.

\section{GENERAL DISCUSSION}

The results of this study indicate that the way in which a person reviews a witnessed event can affect that person's susceptibility to misleading postevent information. Relative to participants who were told to produce a summary account of the witnessed event, participants who were told to construct a detailed account (1) were more verbose in their written accounts and were more likely to include event and postevent suggested items, and (2) were more likely to mistakenly attribute the suggested items to the event on a final source memory test, even if they did not write down the suggested item during the review. Furthermore, Experiment 2 demonstrated that these effects are not found if the review takes place before participants are exposed to postevent misinformation, indicating that the results of Experiment 1 are not explained by a criterion shift. Instead, the results suggest that the participants in the detail review condition were more likely than the 
summary review participants to retrieve suggested items (including items that were not written down) in the context of remembering the witnessed event.

One theoretical account of our findings is provided by the source-monitoring framework (SMF; Johnson et al., 1993). According to this account, source memory decisions are made by comparing the amount and nature of the characteristics associated with a memory trace to expectations about the characteristics of memory from different sources. Errors can occur when memory traces have characteristics normally associated with a different source. In the context of this study, the SMF would suggest that participants in the detail review condition were more likely to think about (and produce) postevent suggestions while recollecting the events in the video than were participants in the summary review condition. Thus, these participants may have been more likely to form an image of the suggested item and/or associate the item with contextual details from the events in the video. This process would make the characteristics of these suggested items more "event-like" and consequently more likely to be attributed to the video during the source test.

One interesting aspect of our study is that the results are, in many ways, counterintuitive. Most people (including potential jurors) would be likely to say that a thorough, careful review of one's memory for an eyewitness event is almost certainly likely to lead to greater accuracy. In some sense they would be correct. If we consider just the written product of the review, the detail review instructions increased recall of both event and postevent details relative to the summary review. Thus, the instructions led participants to recall more information. However, the process of engaging in a detailed review had negative consequences that were not apparent until the final source test. Specifically, the detailed review actually rendered participants less able to accurately ascertain the source of the postevent suggestions under conditions that encouraged close scrutiny of their memories. We note that this finding is relevant to research on the Cognitive Interview (CI; Fisher \& Geiselman, 1992), a technique used to facilitate recall of eyewitness events. Our detail review instructions bear a strong resemblance to the "Report Everything" component of the technique. Furthermore, it has been argued that the CI technique as a whole leads to both increased accurate and erroneous recall (Memon \& Stevenage, 1996; Memon, Wark, Holley, Bull, \& Koehnken, 1997; but see Fisher, 1996). Although we have not tested the CI technique in this study, our findings raise the possibility that instructions used in this procedure have the potential to solidify erroneous memories when witnesses have been previously exposed to misleading postevent information.

Although the present study demonstrates that a detailed review following postevent suggestion can increase source misattribution errors more than can a summary review, we do not argue that a detailed review will always lead to poorer performance. The effect of specificity of review is likely to interact with the type of postevent information that is suggested. Most of the suggestions used in this study were fairly peripheral aspects of the event (e.g., the thief pulled a window shade down), which is typical for eyewitness suggestibility research. Thus, it is not surprising that a detailed review, relative to a summary review, increased the incorporation of these types of suggestions. If the suggestions were more central to the event, participants could be just as likely to think about and include these details (and increase the likelihood of source misattribution errors) in a summary review as in a detailed one. However, there is a caveat. Postevent misinformation that is more central may be more difficult for participants to accept, because it more obviously conflicts with memory for the event, and in some cases, may actually make them scrutinize postevent information more closely (Loftus, 1979).

The task of a witness is difficult. The encoding of witnessed events can occur under less than ideal circumstances, and often considerable time passes between the occurrence of the event and when a witness is called to testify. Common sense suggests that one way to preserve memory is to review the details of what happened. The results of this study and related research (e.g., Hashtroudi, Johnson, Vnek, \& Ferguson, 1994; Koutstaal et al., 1999; Mather \& Johnson, 2000, 2001) suggest that not all reviews are equal in their effects on memory. Reviewing is inherently selective, and this can lead to both increased accuracy and increased error.

\section{REFERENCES}

Bornstein, B. H., Liebel,L. M., \& Scarberry,N. C. (1998). Repeated testing in eyewitness memory: A means to improve recall of a negative emotional event. Applied Cognitive Psychology, 12, 119-131.

Brainerd, C. J., Reyna, V. F., Howe, M. L., \& Kingma, J. (1990). The development of forgetting and reminiscence. Monographs of the Society for Research in Child Development, 55 (3-4, Serial No. 222).

Chambers, K. L., \& Zaragoza, M. S. (1993, November). The effect of source credibility and delay on eyewitness suggestibility. Poster presented at the 34th Annual Meeting of the Psychonomic Society, Washington, DC.

Dunning, D., \& STERn, L. B. (1992). Examining the generality of eyewitness hypermnesia: A close look at time delay and question type. Applied Cognitive Psychology, 6, 643-657.

ERDELYI, M. H. (1996). The recovery of unconscious memories: Hypermnesia and reminiscence. Chicago: University of Chicago Press.

ERDELYI, M. H., \& BECKER, J. (1974). Hypermnesia for pictures: Incremental memory for pictures but not words in multiple recall trials. British Journal of Social \& Clinical Psychology, 18, 41-51.

Eugenio, P., Buckhout, R., Kostes, S., \& Ellison, K. (1982). Hypermnesia in the eyewitness to a crime. Bulletin of the Psychonomic Society, 19, 83-86.

FISHER, R. P. (1996). Misconceptions in design and analysis of research with the Cognitive Interview. Psycoloquy, 7 (35).

Fisher, R. P., \& Geiselman, R.E. (1992). Memory enhancing techniques for investigative interviewing: The Cognitive Interview. Springfield, IL: Charles C. Thomas.

Fivush, R, \& Hamond, N. R. (1989). Time and again: Effects of repetition and retention interval on 2 year olds' event recall. Journal of Experimental Child Psychology, 47, 259-273.

Greene, E., Flynn, M. S., \& Loftus, E. D. (1982). Inducing resistance to misleading information. Journal of Verbal Learning \& Verbal Behavior, 21, 207-219. 
Hashtroudi, S., Johnson, M. K., Vnek, N., \& Ferguson, S. A. (1994). Aging and the effects of affective and factual focus on source monitoring and recall. Psychology \& Aging, 9, 160-170.

Hogan, R. M., \& Kintsch, W. (1971). Differential effects of study and test trials on long-term retention and recall. Journal of Verbal Learning \& Verbal Behavior, 10, 562-567.

Howe, M. J. (1970). Repeated presentation and recall of meaningful prose. Journal of Educational Psychology, 61, 214-219.

Howe, M. L. (1991). Misleading children's story recall: Forgetting and reminiscence of the facts. Developmental Psychology, 27, 746-762.

Johnson, M. K., Hashtroudi, S., \& Lindsay, D. S. (1993). Source monitoring. Psychological Bulletin, 114, 3-28.

KAY, H. (1955). Learning and retaining verbal material. British Journal of Psychology, 46, 81-100.

Koutstaal, W., Schacter, D. L., Johnson, M. K., \& GallucCIO, L.(1999). Facilitation and impairment of event memory produced by photograph review. Memory \& Cognition, 27, 478-493.

LiNDSAY, D. S. (1990). Misleading suggestions can impair eyewitnesses' ability to remember event details. Journal of Experimental Psychology: Learning, Memory, \& Cognition, 16, 1077-1083.

LofTUS, E. F. (1979). Reactions to blatantly contradictory information. Memory \& Cognition, 7, 368-374.

Loftus, E. F., Miller, D. G., \& Burns, H. J. (1978). Semantic integration of verbal information into a visual memory. Journal of Experimental Psychology: Human Learning \& Memory, 4, 19-31.

Mather, M., \& Johnson, M. K. (2000). Choice-supportive source monitoring: Do our decisions seem better to us as we age? Psychology \& Aging, 15, 596-606.

Mather, M., \& Johnson, M. K. (2001). Affective review and schema reliance in older and younger adults. Manuscript submitted for publication.

McCloskey, M., \& Zaragoza, M. (1985). Misleading postevent information and memory for events: Arguments and evidence against memory impairment hypotheses. Journal of Experimental Psychology: General, 114, 3-18.

Memon, A., \& Stevenage, S. V. (1996). Interviewing witnesses: What works and what doesn't? Psycoloquy, 7 (06).

Memon, A., Wark, L., Holley, A., Bull, R., \& Koehnken, G. (1997). Eyewitness performance in cognitive and structured interviews. Memory, 5, 639-656.

Mitchell, K. J., \& Zaragoza, M. S. (1996). Repeated exposure to suggestion and false memory: The role of contextual variability. Journal of Memory \& Language, 35, 246-260.

PAYNe, D. L. (1987). Hypermnesia and reminiscence in recall: A historical and empirical review. Psychological Bulletin, 101, 5-27.

Poole, D. A., \& White, L. T. (1991). Effects of question repetition on the eyewitness testimony of children and adults. Developmental Psychology, 27, 975-986.

RabbitT, P., \& Winthrope, C. (1998). What do old people remember? The Galton paradigm reconsidered. In M. M. Gruneberg \& P. E. Morris (Eds.), Practical aspects of memory: Current Research and Issues: Vol. 1. Memory in everyday life (pp. 301-307). New York: Wiley.

RICHARDSON, J. T. (1985). The effects of retention tests upon memory: An historical review and an experimental analysis. Educational Psychology, 5, 85-114.

Roediger, H. L., III, \& JAcoby, J. D., \& McDermott, K. B. (1996). Misinformation effects in recall: Creating false memories through repeated retrieval. Journal of Memory \& Language, 35, 300-318.

Roediger, H. L., III, \& NeELy, J. H. (1982). Retrieval blocks in episodic and semantic memory. Canadian Journal of Psychology, 36, 213-242.

Schooler, J. W., Foster, R. A., \& Loftus, E. F. (1988). Some deleterious consequences of the act of recollection. Memory \& Cognition, 16, 243-251.
Scrivner, E., \& SAfer, M. A. (1988). Eyewitnesses show hypermnesia for details about a violent event. Journal of Applied Psychology, 73, 371-377

Shaw, J. S., III, BJork, R. A., \& Handal, A. (1995). Retrieval-induced forgetting in an eyewitness-memory paradigm. Psychonomic Bulletin \& Review, 2, 249-253.

Suengas, A. G., \& Johnson, M. K. (1988). Qualitative effects of rehearsal on memories for perceived and imagined complex events. Journal of Experimental Psychology: General, 117, 377-389.

Tessler, M., \& Nelson, K. (1994). Making memories: The influence of joint encoding on later recall by young children. Consciousness \& Cognition, 3, 307-326.

Tousignant, J. P., Hall, D., \& Loftus, E. F. (1986). Discrepancy detection and vulnerability to misleading postevent information. Memory \& Cognition, 14, 329-338.

Warren, A. R., \& LANE, P. (1995). Tell me again and again: Stability and change in the repeated testimonies of children and adults. In M. S. Zaragoza, J. R. Graham, G. C. N. Hall, R. Hirschman, \& Y. S. Ben-Porath (Eds.), Memory and testimony in the child witness (pp. 44-60). Thousand Oaks, CA: Sage.

Zaragoza, M. S., \& LANE, S. M. (1994). Source misattributions and the suggestibility of eyewitness memory. Journal of Experimental Psychology: Learning, Memory, \& Cognition, 20, 934-945.

Zaragoza. M. S., \& Mitchell, K. J. (1996). Repeated exposure to suggestion and the creation of false memories. Psychological Science, 7, 294-300.

\section{NOTES}

1. Repetition was manipulated in the present study to examine whether the effects of review were greater for items that were better remembered from the questions (i.e., thrice $>$ once suggested items). As noted in the results, although suggestibility increased with repetition, the effect did not interact with type of review.

2. Some readers may note that the test format for this study differs from the four-alternative single question format (i.e., "saw," "read," "both," "neither") often seen in source memory studies. In previous studies (e.g., Zaragoza \& Lane, 1994, Experiment 5), we have found that estimates of source misattributions to the witnessed event obtained with the separate yes/no source question format used in this study are virtually identical to those obtained with a four-alternative format. In fact, the separate question format was originally used as a response to claims that a "both" response in the four-alternative format was simply a "compromise" response when participants were unsure of the source.

3. Follow-up analyses revealed that the group differences in attributing suggested items to the video was not a result of group differences in the overall likelihood of recognizing the suggested items (i.e., attributing them to either the video or the suggestions), because overall recognition of suggestions did not differ by group. The proportion of suggestions correctly attributed to only the questions also did not differ between groups. Instead, the effect was due to group differences in the number of suggestions that were attributed to both the video and the questions, $[F(2,267)=3.34, p<.05]$. Post hoc Tukey tests revealed that detail review participants made more "both" attributions $(M=.40, S E=$ $.03)$ than did summary review participants $(M=.30, S E=.02)$. Control participants were in between $(M=.36, S E=.03)$ and did not significantly differ from the other groups. Thus, participants in the detail review condition were as accurate at correctly remembering that the suggestions had been in the questions, but were more likely to also incorrectly attribute the suggestions to the video.

(Manuscript received August 19, 1999; revision accepted for publication July 22, 2001.) 